\title{
ATRIBUTOS LABORATIVOS EM ATIVIDADES CARACTERÍSTICAS DO TURISMO (ACTs): A SERVIÇO DA HOSPITALIDADE PRODUTIVA
}

\author{
Labor attributes in Activities Characteristics of Tourism (ACTs): in favor of productive hospitality \\ Atributos laborativos en Actividades Características del Turismo (ACTs): en favor de la hospitalidad \\ productiva
}

Rodrigo Meira Martoni

Universidade Federal de Ouro Preto (UFOP), Brasil

DOI: https://doi.org/10.18472/cvt.20n2.2020.1626

Redalyc: http://www.redalyc.org/articulo.oa?

rodrigomartoni@gmail.com

$\mathrm{id}=115464354001$

Recepción: 16 Julio 2018

Aprobación: 20 Abril 2020

\section{Resumo:}

A pesquisa trata das interações socioprodutivas na dinamização dos espaços alcançados pelo turismo. O intuito central é demonstrar que há uma diversidade de questões somente indicadas nas formas aparentes desses espaços, sendo que, o ponto a ser observado e compreendido para se começar a empreender uma ultrapassagem rumo à realidade concreta-pensada deles, é justamente aquele concernente às interações e divisões estabelecidas entre os sujeitos ao levarem a cabo sua produção. Com o propósito de revelar a dinâmica real dos circuitos delimitados, paramentados e motivadores dos fluxos turísticos, inicialmente é realizada uma análise apontando os porquês de a hospitalidade, mediante o formato abstrato do trabalho, se constituir em uma relação efetivamente produtiva, sobretudo naquelas realidades caracterizadas por vantagens de localização. Em seguida, exemplificamos o trabalho produtivo no turismo, relatando, por um lado, a produção de serviços receptivos em territórios considerados como "modelos" e, por outro, certas configurações de ocupações nas chamadas Atividades Características do Turismo (ACTs) no Brasil, bem como alguns dos seus desdobramentos socioespaciais.

\section{Abstract:}

The present research covers the socio-productive interactions on tourist boosting areas. The main purpose is to demonstrate that there are several issues only indicated on the apparent forms of tourist spaces, while the point that should be observed and understood towards their concrete-thought reality is exactly that concerning the interactions and divisions established between the subjects on managing their production. With the purpose to disclose the real dynamics of delimited, adorned and motivating circuits of tourism flows, an analysis is done to point the "whys" of hospitality, based upon the abstract format of work, being a relationship effectively productive, mainly in those areas marked by the advantage of privileged location. Afterwards, the productive work on tourism field is shown, reporting, on the one hand, the production of incoming services in areas considered as "models", and, on the other hand, the configuration of occupations in the so-called Characteristic Activities of Tourism (CATs) in Brazil, as well as some of its socio-spatial developments.

KEYWORDS: productive work, tourism, precariousness.

\section{ReSUMEN:}

La investigación trata de las interacciones socioproductivas en la dinamización de los espacios alcanzados por el turismo. La intención central es demostrar que hay una diversidad de cuestiones sólo indicadas en las formas aparentes de los espacios turísticos, siendo que el punto a ser observado y comprendido para comenzar a emprender un adelantamiento hacia la realidad concretapensada de ellos, es justamente aquello concerniente a las interacciones y divisiones establecidas entre los sujetos al llevar a cabo su producción. Con el propósito de revelar la dinámica real de los circuitos delimitados, paramentados y motivadores de los flujos turísticos, inicialmente se realiza un análisis apuntando a los porqués de la hospitalidad, mediante el formato abstracto del trabajo, constituirse en una relación efectivamente productiva, sobre todo en aquellas realidades caracterizadas por ventajas de localización. A continuación, ejemplificamos el trabajo productivo en el turismo, relatando, por un lado, la producción de servicios receptivos en territorios considerados como "modelos" y, por otro, las configuraciones de ocupaciones en las llamadas Actividades Características del Turismo (ACTs) en Brasil, así como como algunos de sus desdoblamientos socioespaciales.

PAlabras ClaVE: trabajo productivo, turismo, precariedad.

Palabras Clave trabalho produtivo, turismo, precariedade 


\section{CONSIDERAÇÕES INICIAIS}

A separação/espetacularização do espaço para a produção e realização levou Christin e Bourdeau (2011, p. 08) a caracterizarem o turismo como uma espécie de controlador social "[...] en capturant le désir touristique pour le fixer dans certaines pratiques, en certaines lieux, à certaines conditions" ${ }^{[1]}$. Se averiguações delimitam diferentes escalas de acordo com certas qualificações e buscam regulá-las e harmonizá-las via planificações e/ou por uma "cultura" emancipada da economia política, tal afirmação é procedente. Isso significa que, se "l'tourisme s'empare [...] de la réalité afin de lui donner une allure convenable, selon des critères partagés et jugés acceptables en termes esthétiques, sécuritaires, économiques, environnementaux [...]" (Christin, 2011, p. 25) ${ }^{[2]}$, é possível falar do espaço assim caracterizado enquanto mais um instrumento para se exercer controle sobre a sociedade.

Trata-se, aqui, do espaço como "meio" ou "mediação", conforme explica Lefebvre (2008, p. 44), não somente para garantir a "reprodução dos meios de produção", tal como era corrente entre a revolução industrial e o início do século XX. Nesse período do capitalismo concorrencial, a paulatina institucionalização do controle em relação aos afazeres do trabalhador em seu (diminuto) tempo livre, associada, sobretudo, ao "sistema contratual (o contrato de trabalho) [e ao] sistema jurídico (o código civil e o código penal) quase bastavam para assegurar, com a venda da força de trabalho, essa re-produção dos meios de produção" (Lefebvre, 2008, p. 47). Mas, se tal interação social (produção socializada - apropriação privada - salário/pagamento - troca - consumo) é permeada por inovações em termos absolutos e relativos em novas frentes produtivas, Lefebvre evidencia que os mecanismos para a "re-produção das relações de produção" se impõem paralelamente, questão essa que efetua-se "[...] através da cotidianidade, através dos lazeres e da cultura $[\ldots] ”$.

Sendo o espaço "elemento necessário a toda produção e a toda atividade humana" (Marx, 2008, v. IV, p. 1026), ele constitui-se, então, como veículo para essa reprodução. Baseando a produção material e imaterial as quais o capital interpõe-se de forma cada vez mais alargada, enraizada e contraditória (o trabalho útil produtivo como relação dominante que subordina outras atividades - o trabalho útil improdutivo - e institui novas para se expandir), o espaço efetiva-se como mecanismo de preservação das relações sociais vigentes via disjunção e projeção de indícios como se fossem totalidades. Mas, diante de espacialidades também como mediações-controladoras e, portanto, peça-chave da burguesia e das relações que a favoreçam enquanto classe se abre a seguinte indagação: como isso se efetiva? Posto que, tanto as descrições da empiria como as concepções idealistas não teriam como apontar esclarecimentos que estivessem além das dimensões em que trabalham (e para quem trabalham), consideramos que, a reboque deste questionamento, impóe-se a necessidade de conbecer e explicar a forma como o espaço é produzido.

Para tal desafio, Lefebvre (2008, pp. 22-24) faz duas advertências preliminares: 1) sempre que o enfoque científico é parcelar, tanto do ponto de vista de um campo do conhecimento como de uma porção do espaço recortada e delimitada em suas singularidades (culturais, ecológicas, sócio-organizativas, arquitetônicas, históricas) por si mesmas - e, portanto, desconectadas da formação social (capitalista) - fatalmente concretizase uma “[...] falsa análise [...] que se julga precisa, porque visual, dos lugares e localizações"; 2) frente a questão da fragmentação, que se firma habilidosamente para a "reprodução das relações de produção" ou contribui casualmente com ela diante da "consciência ingênua" (Kosik, 1976, p. 15), a reflexão abrangente em relação à produção do espaço não diz respeito ao empreendimento intelectual de se "localizar no espaço preexistente uma necessidade ou uma função, mas, ao contrário, [...] de espacializar uma atividade social, ligada a uma prática no seu conjunto [...]".

Partindo do princípio de que há uma diversidade de questões somente indicadas nas formas aparentes dos espaços alcançados pelo turismo, o ponto a ser observado e compreendido para se começar a empreender uma ultrapassagem rumo à realidade concreta-pensada deles, é justamente aquele concernente às interações e divisões estabelecidas entre os sujeitos ao levarem a cabo sua produção, afinal, "[...] os 
lugares de lazeres [...], aos quais se procura dar um ar de liberdade e de festa, que se povoa de signos que não tem a produção e o trabalho por significados, encontram-se precisamente ligados ao trabalho produtivo" (Lefebvre, 2008, pp. 49, 50). Com esse propósito, ou seja, o de revelar a dinâmica real dos circuitos delimitados, paramentados e motivadores dos fluxos turísticos, inicialmente é realizada uma análise apontando os porquês de a hospitalidade, mediante o formato abstrato do trabalho, se constituir em uma relação efetivamente produtiva, sobretudo naquelas realidades caracterizadas por vantagens de localização. Em seguida, exemplificamos o trabalho produtivo no turismo, relatando, por um lado, a produção de serviços receptivos em territórios considerados como "modelos" e, por outro, as configurações concretas das ocupações nas chamadas Atividades Características do Turismo (ACTs) ${ }^{[3]}$ no Brasil, bem como alguns dos seus desdobramentos socioespaciais.

\section{Trabalho produtivo no tURismo}

Os referenciais estético-produtivos de destinações emblemáticas, principalmente nos chamados países centrais, corriqueiramente são postos como "modelos". Paralelamente, os mesmos estudiosos do turismo que os evidenciam tecem críticas quanto aos patamares de qualidade alcançados no campo dos serviços ligados à hospitalidade em territórios periféricos, almejando confrontar tais realidades pela força do exemplo. Ao denunciar com muita originalidade e pertinência as calúnias e fantasias expostas a respeito do turismo no Brasil pelo Ministério encarregado do setor em vídeos publicitários intitulados "você vive em um país perfeito para viajar," veiculados em 2014, Trigo (2014) ${ }^{[4]}$ relata que, no quesito turismo, "melhoramos em vários pontos nos últimos vinte anos, mas ainda estamos há uma distância imensa de padróes de qualidade internacionalmente respeitados [pois, dentre outras coisas] a formação profissional é pobre”.

Nesse sentido, Trigo (2014) enfatiza as habilidades requeridas da mão de obra em turismo para que o país seja alçado a graus equivalentes aos de destinações "modelos" e, ao mesmo tempo, condena toda e qualquer organização política e de classe, defendendo que "se almejamos um turismo respeitado neste país, temos que lutar pela qualidade técnica e holística de nossos estudantes e profissionais [ao mesmo tempo em que é um engano] insistir em algo que é arcaico, inútil e que não resolverá os nossos problemas que é a regulamentação de uma série de profissões ligadas a viagens e turismo [...]" (Trigo, 2012) ${ }^{[5]}$. Pode-se afirmar que Trigo é um exímio defensor do trabalho produtivo, possibilitado, preferencialmente, pela formação "técnica e holística" para a qualidade total e fluída pela desorganização política da chamada "classe-que-vivedo-trabalho" (Antunes, 2009, p. 103) ${ }^{[6]}$.

Mas o que seria o trabalho produtivo nos serviços turísticos? Compreendemos que um serviço é oferecido (vendido) e deve propiciar uma transformação para o sujeito que dele usufrui. Caracteriza-se, portanto, por algo realmente existente e desvinculado de uma materialidade no sentido de usufruto do seu valor de uso em tempo posterior, sendo que o seu consumo é concomitante à produção e o próprio efeito imaterial do trabalho se constitui como mercadoria:

Quando as camareiras em hotéis ou motéis [...] arrumam camas, realizam uma operação de montagem que não difere muito das ocupações de montagem nas oficinas - fato reconhecido pela gerência quando empreende estudos do movimento e do tempo de ambos nos mesmos princípios - e o resultado é uma mercadoria tangível e vendável. (Braverman, 1980, pp. 304-305).

Se, para o turismo se desenvolver em uma localidade têm-se como referenciais certas "vantagens de localização" (Chesnais, 1996, p. 203), tais como atributos patrimoniais, infra-estrutura, isenção de tributos (e demais incentivos por parte do Estado), mão de obra barata, tais "potencialidades" serão transformadas em "produtos" a partir do trabalho que tem seus resultados muito limitados quando tratamos do produtordireto, ou seja, aquele que opera por si. Nesse sentido, o "desenvolver" na economia capitalista é um conceito que firma-se fundamentalmente no conjunto de estruturas que não poderiam funcionar de 
forma individualizada; não são postas com esse propósito; ou mesmo acabam reconfiguradas no percurso (fechadas, absorvidas, ampliadas), muito embora produtores-diretos continuem a existir, seja por limitações materiais que não os aniquilem enquanto tais (em realidades socioespaciais pouco interessantes aos processos reprodutivos do capital, por exemplo), seja para atender a outros e novos capitais em momentos e espaços definidos, inclusive aqueles que formatam monopólios e oligopólios.

O fato a ser ressaltado é que os serviços prestados como mercadorias (produção socializada) serão produtivos pela relação que encerram, ou seja, ao serem executados precisam necessariamente gerar um valor superior ao que é despendido na forma de salário ou pagamento (capital variável) e que fica com o empregador, sendo utilizado na reprodução simples e ampliada do capital, além de aplicado em meios que gerem diferentes tipos de rendas:

[...] O conceito de trabalho produtivo não compreende apenas uma relação entre atividade e efeito útil, entre trabalhador e produto do trabalho, mas também uma relação de produção especificamente social, de origem histórica [capitalista], que faz do trabalhador o instrumento direto de criar [mais-valor]. Ser trabalhador produtivo não é nenhuma felicidade, mas azar. (Marx, 2001, v. II, p. 578).

Nesse sentido, se o serviço puder ser executado diretamente e, portanto, sem a intermediação de outros sujeitos, mesmo que ele seja útil e gere valor (mercadoria), não é considerado produtivo do ponto de vista do capital. A questão primordial é que o valor-capital, para ser produzido e reproduzido, precisa da absorção de sujeitos como classe trabalhadora (contratados por serviço, assalariados, terceirizados) bem como da continuidade e do cuidado para que assim permaneçam. Sem isso, conforme destaca Marx (2001, v. II, p. 883) “[...] são impossíveis a acumulação capitalista e o modo capitalista de produção".

Por mais que os proprietários de empresas de serviços turísticos gostem eventualmente de bem receber, seus empreendimentos precisam ser realizados no mercado. Dessa forma, toda e qualquer unidade de capital adiantada na produção não tem como mediação principal o valor de uso, mas sua materialidade e/ou imaterialidade como algo indispensável à produção para a troca. Por isso, necessariamente, aquele indivíduo ou grupo que personifica o capital (exercendo o seu papel social e não pessoal) deve "produzir uma mercadoria de valor mais elevado que o valor conjunto das mercadorias necessárias para produzi-la, isto é, a soma dos valores dos meios de produção e força de trabalho" (Marx, 2008, v. I, p. 220). E não se trata da diferença estabelecida entre investimentos de capital ou o chamado custo de produção (capital constante e variável) e o preço realizado dos serviços, uma vez que "a categoria preço de custo nada tem a ver com a produção do valor da mercadoria ou com o processo de valorização do capital” (Marx, 2008, v. I, p. 43).

Se, para o agente-contratante, o total despendido para se prestar um serviço de hospedagem, por exemplo, consiste no montante direcionado à compensação e manutenção da unidade produtiva (financiamentos, reformas), mais os gastos com materiais de consumo e empregados, lhe foge o fato de que para essa mercadoria atender aos seus propósitos é necessário o processo de valorização do valor anteriormente investido. Para ele, tudo seria custo de produção e o lucro resultaria meramente da diferença entre o capital adiantado (preço de custo) e o preço médio de mercado (valor de troca da mercadoria), referente a prestação de serviços na categoria do seu meio de hospedagem.

Mas, se a própria forma social capitalista acoberta o fato de que somente o trabalho gera valor e promove sua variação concretizando o mais-valor, enquanto o meio de produção tem o seu valor transferido ao preço de venda (ou seja, o capital explora somente o trabalho vivo), é preciso desmistificar a confusão que se faz quando erroneamente se identifica o capital variável com o constante; o que equivale a dizer que o lucro seria resultante do empreendedorismo do capitalista ou uma relação de todo o capital adiantado com o capital auferido, sendo a intermediação do trabalho simplesmente um fator de produção em que o salário entraria como seu equivalente total e a venda originaria o mais-valor. Nada mais enganoso: o preço da força de trabalho jamais pode ser identificado com o valor que o trabalho produz, além do que o mais-valor não se constitui em "excesso do preço de venda sobre o valor da mercadoria, [mas sim em] excesso desse valor sobre o preço de custo" (Marx, 2008, v. IV, p. 53). 
Isso significa que, uma vez estabelecido o contrato de trabalho legitimado pelo Estado de direito e pela relação contratante-contratado, não há necessariamente injustiça na esfera da troca de capacidades laborativas por dinheiro, pois o valor dessa força física e intelectual é previamente combinado entre esses dois sujeitos sociais e somente entra em operação após tal acordo. Fundamentalmente, o ônus que recai sobre o trabalhador, qualificado ou não, vem do seu posicionamento enquanto classe social, ou seja, enquanto indivíduo que não tem possibilidades de produzir com seus próprios meios (ou esses instrumentos estão cerceados aos processos reprodutivos do capital), sendo a sua especificidade de acrescer valor (o trabalho abstrato) que o coloca em relação com o agente capitalista e somente ele justifica a sua cota-parte nessa distribuição desigual. A apropriação do que se gera por essa atividade social é o dinheiro que se transforma em capital. Braverman (1980, p. 349) esclarece: "O capital é assim não o dinheiro trocado por trabalho; é dinheiro trocado por trabalho com o objetivo de apropriar-se daquele valor que ele cria no que é pago e acima do que é pago". Seus representantes, uma vez expostos à lógica da concorrência, podem um dia deixar esse posto caso não estejam empenhados em estabelecer estratégias para expandi-lo; assim como alguns poucos integrantes da classe trabalhadora podem passar a representá-lo, desde que obtenham meios que lhes permitam se valer do trabalho excedente alheio e/ou a se relacionarem com outros indivíduos via obtenção de um capital acumulado que lhes propiciem rendas e juros para além dos seus gastos reprodutivos.

Ao situarem a qualificação e o esmero profissional como questóes puramente subjetivas e independentes da sociabilidade permeada pelo movimento do capital, não são poucos os especialistas do campo de estudos do turismo que deixam de captar as interações laborativas de caráter efetivamente produtivo que medeiam as mais diversas atividades ligadas à hospitalidade. E, diante dessa emancipação das ideias em relação à economia política, eles também entendem que as ações do Estado e suas planificações nada têm a ver com a forma valor dominante (o capital), mas com um tipo de racionalidade que se move por si e, fatalmente, elevará a forma política ao patamar de máxima correspondência aos anseios de todos os indivíduos. Não é por outro motivo que a França é apontada por Trigo (2014) como um dos países “top ten da área” e, portanto, como território detentor de um "turismo respeitado". Mas, essencialmente, quais os exemplos concernentes à produção do turismo neste país?

\section{Práticas representativas do trabalho produtivo}

É evidente que a configuração territorial que favorece o turismo francês, incluindo aí sua estrutura receptiva, não pode ser equiparada à brasileira, haja vista que a constituição desses países é dispare pelos movimentos sociais e políticos próprios às suas condições históricas, assim como é preciso considerar que diversas decisões e ações definidoras e redefinidoras de nações como o Brasil foram e são tomadas segundo interesses forâneos associados às elites internas e ocultados por uma democracia limitante ao voto, fato que concretiza mais desproporções e disparates socioespaciais. Mas, se há nuances consideráveis, o fundamento da organização da produção material e imaterial da vida social é o mesmo, sendo que suas relações e contradições devem ser observadas no campo do turismo.

Inicialmente deve-se salientar que o levantamento estatístico do Insee (Institut National de la Statistique et des Études Économiques de la France) atribui às atividades turísticas uma graduação concernente à intensidade de um uso mais ou menos voltado a essa finalidade. Por exemplo: os hotéis, as estações de esqui, as agências de viagens e os serviços de recreação seriam 100\% turísticos; as atividades ligadas à restauração (restaurantes, bares, cafés) seriam fortemente turísticas; e as esportivas seriam medianas. Além disso, a esses equipamentos são associados os atrativos locais, bem como aqueles na área de abrangência das bacias hidrográficas, definindo as regiões mais ou menos turísticas em função dos "types d'espaces" [7], como montanhas, praias, zonas rurais e urbanas, entre outros. A partir dessa diferenciação é possível estabelecer de forma mais exata o número de empregos formais gerados especificamente pelo turismo. No Brasil, o Ipea (Instituto de Pesquisa Econômica Aplicada) aplica um procedimento com o mesmo propósito ao desenvolver 
pesquisas quanto às ocupações no setor, chamado Sistema Integrado de Informações sobre o Mercado de Trabalho no Setor de Turismo (Simt). Trata-se do chamado "coeficiente turístico", uma pesquisa realizada por telefone para a verificação dos atendimentos realizados exclusivamente a turistas em estabelecimentos enquadrados no rol das ACTs.

Importa observar que os grupos que mais geram ocupações nesse setor são os de restauração e alojamento, tanto na França como no Brasil, e, em relação aos empregos informais, "le recensement de la population est une source qui permet d'estimer l'emploi non salarié pour les seules activités considérées comme $100 \%$ touristiques" (Insee, 2012) ${ }^{[8]}$. Contudo, como adverte o próprio Insee, as estimativas acerca dessas ocupações não retratam a realidade anual, uma vez que se janeiro é o período do recenseamento, esse mês é também marcado pelas contratações temporárias em estações de inverno e pela minimização dos quadros em regiões litorâneas. Ao apontar a sua importância para a economia da França exemplificando o caso da região do MidiPyrénées, o Insee (2012) assegura que "les emplois dans le tourisme, qu'ils soient saisonniers ou non, sont moins qualifiés, plus souvent à temps partiel et moins souvent en CDI [Contrat à Durée Indéterminée] que la moyenne"[9].

Embora as ocupações nos centros urbanos maiores sejam menos influenciadas pela sazonalidade, os balneários, os vilarejos situados em regiões montanhosas ou mesmo as pequenas comunidades rurais têm movimentação fortemente associada às estações e/ou períodos de férias, fato que contribui para que parte expressiva dos empregos disponibilizados em ACTs sejam caracterizados pela temporalidade diminuta. No que se refere especificamente aos empregados sazonais, toma vulto as discussões quanto à ingerência social para o capital dessas contratações, as quais têm se firmado como meio de minimização de custos para atender as exigências temporais e de lucros para a competitividade, sobretudo nas empresas de pequeno porte, as quais têm expressiva participação na dinâmica do turismo francês. Dethyre (2007, p.74) explica que "parmi les deux millions d'emplois connus et reconnus dans le secteur du tourisme, beaucoup sont de caractère saissonier au moins $25 \%$ - avec une tendence à l'accroissement" $\left.{ }^{\text {" }} 10\right]$.

O empregado por temporada pode estar amparado por um contrato chamado de "sazonal" que é uma espécie de acordo de trabalho por tempo determinado, reconhecido legalmente na França como um tipo de Contrat à Durée Déterminée (CDD) ${ }^{[11]}$, muito embora não possua as mesmas particularidades desse último, pois, ao trabalhador regido por ele, não é dado o direito, por exemplo, de recebimento de $10 \%$ da remuneração bruta ao fim do período tal como aquele regulado pelo CDD. Por não contemplar garantias mínimas, esse tipo de vínculo entre patrão e empregado é apontado por movimentos encabeçados pela classe trabalhadora e organizações sindicais como algo ainda mais precário que o CDD e, se inicialmente ele era comum aos postos de trabalho totalmente ligados ao turismo, sua extensão às ocupações desse setor e a outras atividades correlatas ou não (como museus, postos de combustível, bancos) é vista como uma maneira de minimização de custos com o trabalho vivo, por isso a tendência à sua dilatação. Conforme apontado nas duas edições (2010 e 2012) do Forum Social des Saisonniers em Aubagne (Departamento de Bouches-du-Rhône, França), "le contrat saisonnier [dans le tourisme] sert de laboratoire à la précarisation du travail [parce que] le gestionnaire confronté à des contraintes de gestion dira: "On fait rentrer la lame là où on pense encontrer le moins de résistence" ${ }^{[12]}$.

Segundo Dethyre (2007, p. 69), se existem contratações formais, mesmo que temporárias ou em tempo parcial, diversas são as dificuldades para se auferir informações confiáveis quanto ao trabalho no turismo, “[...] notamment en raison du travail au noir dans les hôtel, cafés et restaurants [...]" [13], questão essa constantemente salientada pela Confédération Générale du Travail (CGT $)^{[14]}$. O fato é que a informalidade (sazonal ou não) acentua a possibilidade de se estender e intensificar os períodos laborais, favorecendo a geração de mais-valor tanto em sua forma absoluta como relativa. Uma enquete realizada pela Jeunesse Ouvrière Chrétienne (JOC) ${ }^{[15]}$ e distribuída no Fórum Social de 2012, aponta que os sujeitos que precisam recorrer a trabalhos dessa natureza pela falta de emprego e/ou de Contratos com Tempo Indeterminado 
(CDI), procuram auferir ganhos para suprir os meses em que não encontram ocupação, fato que, associado às regras para a acumulação a serem seguidas pelos contratantes, também favorece a extensão de horas e dias sem pausas, conforme denuncia Dethyre (2007, p. 74):

La saison est courte pour le tourisme estival, ce qui pousse les employeurs à tenter de réaliser le plus gros chiffre d'affaires durant cette période [...]. Les organisations syndicales dénoncent, par exemple, le fait que des 'établissements' de 'front de mer' emploient des jeunes mal payés accomplissant plus de cent heures de travail par semaine ${ }^{[16] \text {. }}$

Isso significa 16 a 17 horas por dia se incluídos os sábados, fazendo-nos lembrar das difíceis condições de vida dos trabalhadores nas indústrias inglesas de meados do século XIX denunciadas por Marx, Engels, Lafargue, entre outros. A diferença, no entanto, é que nesses casos trabalha-se um pouco mais. $\mathrm{Na}$ França foi registrada uma movimentação de 83,8 milhões de turistas estrangeiros em $2014^{[17]}$, sendo a atividade responsável por 7,4\% do Produto Interno Bruto nesse mesmo ano (abarcando aí os deslocamentos domésticos), além de que quase $7,7 \%$ dos empregos formais do país em tempo integral são registrados nas ACTs. Conforme relatado, a maior parte das ocupações está nas pequenas unidades produtivas de serviços, sendo que a média de trabalhador por empresa é de 3,6 pessoas ${ }^{[18]}$. Em pesquisa do Insee a respeito do custo da mão de obra na França, considerada cara diante de países da União Europeia como a Bélgica, a Suécia e a Dinamarca, evidenciou-se que tal custo aumenta com o tamanho da empresa diante das obrigações legais concernentes aos contratos formais de trabalho.

Mas, considerando que isso não se aplica à parte expressiva dos empreendimentos turísticos, verifica-se que a média salarial no setor é mais baixa que o conjunto da economia, mesmo ao se levar em conta as ocupações formais e em tempo integral: a partir de dados do Insee ${ }^{[19]}$ constata-se, por exemplo, que se a totalidade dos salários na região do Midi-Pyrénées correspondiam em 2009 a média de $1884 €$ por mês, no turismo esses eram de $1427 €$. Diante disso, Berodias (2012) ${ }^{[20]}$, uma recepcionista em contrato sazonal em um centro de férias da Életricité de France (EDF) ${ }^{[21]}$, chama a atenção não somente para a precariedade, mas para a tendência à precarização, uma vez que se os ganhos menores são geralmente acompanhados de horas laborais mais extensas e intensas em atividades do setor de turismo, em se tratando dos contratos sazonais os pagamentos costumeiramente são mensurados conforme o mínimo legal (de 7,47€ líquido por hora em 2014) ${ }^{[22]}$, quando não ficam abaixo desse patamar diante da falta de contratos. Soma-se a isso o fato de que fica difícil saber se haverá trabalho ao fim de uma temporada e, se houver, por quanto tempo ele estará garantido.

Berodias esclarece ainda "que l'Etat contribue à la précarité de l'emploi, car il ne prend que peu en compte la réalité du travail saisonnier" ${ }^{[23]}$ : instituições estatais apresentaram ao longo dos últimos anos diversos relatórios sobre a precariedade do emprego com foco nas ocupações sazonais, tais como "Le rapport Gaymard sur la pluriativité" [24], de 1994; "Le rapport Anicet Le Pors sur les saisonniers"[25], de 1999; "Le rapport Simon sur le logement" ${ }^{[26]}$, de 2005; "Le rapport Vansonn sur les emplois en montagne" ${ }^{[27]}$, de 2011; além de que diversos estudos produzidos regionalmente foram publicizados apontando tanto a realidade como possíves formas de amenização, contudo, “depuis plus de 25 ans, concrètement, il n'en est réellement rien ressorti pour l'amélioration de la vie et des conditions de travail des saisonniers, alors qu'en 25 ans le nombre de saisonniers a augmenté" (Berodias, 2012) ${ }^{[28]}$. Contratos que preveem um período mínimo de trabalho de quatro meses e a continuidade das contratações de uma temporada à outra (gerando garantias como segurodesemprego) e o pagamento do mínimo legal por horas laborais alongadas prejudicam as contas públicas, a eficiência dos negócios e a competitividade no turismo e, por isso, nada ocorreu no campo da legislação no sentido de reconhecer tais especificidades laborais e respaldar os indivíduos que delas dependem.

É preciso considerar, no entanto, que o Fórum Social des Saisonniers é uma iniciativa de intelectuais e trabalhadores em atividades características do turismo que, tanto expõe essa realidade como busca lutar contra esse processo em conjunto com centrais sindicais como a Confédération Générale du Travail (CGT), a qual organiza caravanas em épocas específicas do ano com a finalidade de reunir trabalhadores, não somente 
para chamar a atenção para os seus direitos (mesmo que mínimos quando contratados de forma avulsa), mas, mormente, para promover a consciência de classe. A flexibilidade que marca as ocupações e que não é questionada nos cursos de turismo com foco em uma formação cada vez mais tecnicista e operacional (os quais são correntes na França a mais tempo que no Brasil), promove, no fim das contas, a precariedade em nome do empreendedorismo.

Em linhas gerais, tais condições é que fundamentam o "turismo respeitado" (TRIGO, 2012) francês, sendo a força do exemplo posicionada para a eficiência de mercado a partir da qualidade total do produto turístico, ambas advindas, direta e indiretamente, da categoria trabalho produtivo. Mas, enquanto certos sindicatos de trabalhadores na hotelaria e gastronomia no Brasil operam institutos de capacitação profissional divergindo de sua finalidade essencial e, paralelamente, integrantes do chamado saber dominante no turismo apontam que a organização política é um disparate ou, conforme defende Trigo (2012), algo “arcaico" e desnecessário frente à dedicação e preparação individual, é possível afirmar que na França empreende-se uma busca para tratar e debater a dinâmica do real no sentido de orientar ações práticas, obviamente com as dificuldades travadas no âmago dos artifícios expansionistas do capital.

Ou seja, das práticas relacionadas a uma sociabilidade regulada cada vez mais pelo e para o mercado com os chamados laboratórios do produtivismo, os quais não podem deixar de ser sinônimos de precariedade, surge o que podemos chamar de "laboratórios sócio-organizativos", como o Fórum Social des Saisonniers. Mas esses últimos não interessam aos empreendedores-empregadores e alguns estudiosos do turismo no Brasil. As lições que vem do país “top ten" (Trigo, 2012) são justamente àquelas referentes à racionalidade da qualificação e do trabalho não para os trabalhadores, mas para o capital, pois aí está a base da competitividade e possível domínio de mercado. Acerca disso, teceremos considerações adiante.

\section{A ReALidade BRASileira}

O Brasil recebeu 6,4 milhões de turistas estrangeiros em $2014^{[29]}$, sendo a contribuição direta do turismo no Produto Interno Bruto de 3,5\% $\left[^{30}\right]$ nesse mesmo ano. Conforme salienta Trigo (2012) e, de acordo com os dados apontados em relação a França, ainda estamos muito aquém das estatísticas que se explicariam, dentre outras coisas, pelos padrões de qualidade internacionais nos serviços ligados à hospitalidade. Talvez seja por esse motivo que o estrangeiro é posicionado como público de "perfil ideal" (no dialeto do mercado), considerando suas possibilidades de gastos expressivamente mais altos em relação às movimentações domésticas. Assim, não raras vezes, procura-se nivelar a estrutura-suporte nacional em conformidade com o seu poder de compra e, além disso, investir em planos e programas para fomentar esses fluxos. Tais fatos ajudam a caracterizar o turismo interno, considerado de qualidade, como marcadamente caro em termos proporcionais mesmo a países europeus e, portanto, discrepante em relação à média salarial do brasileiro.

Para operacionalizar os serviços turísticos convêm destacar que, em dezembro de 2011, havia 2,078 milhões de pessoas empregadas nas ACTs, sendo 946,7 mil formalizadas (46\%) e 1,131 milhões em ocupações informais (54\%) (Ipea, 2013). Em dezembro de 2013 as ACTs geraram 1.938.955 ocupações, sendo 985.317 formais (ou 50,8\%) e 953.638 informais (ou 49,18\%) (Ipea, 2015). Em relação às informais, o Ipea adverte que a fonte para essa análise é a Pesquisa Nacional por Amostragem de Domicílios (PNAD), a qual possui dimensão reduzida de amostragem quanto às atividades em ACTs, uma vez que é preciso considerar a época em que os dados foram levantados, principalmente em regiões marcadas pela sazonalidade. De forma geral, a informalidade nas ocupações em turismo é expressiva, sendo que na região Nordeste impera as atividades assim caracterizadas. Em termos comparativos, segundo o Ipea (2015), se o Sudeste teve participação de 58\% nos postos formais nas ACTs em 2013, o Nordeste contava somente com $17 \%$ no mesmo ano.

Ouriques (2005, p. 130) observa que, "além de pagar salários inferiores à média nacional, as ocupações nas atividades características do turismo caracterizam-se ainda por estarem nas posições mais baixas da pirâmide salarial brasileira”. Tendo em vista que a média salarial no país foi de $\mathrm{R} \$ 1.928,00 \mathrm{em}$ dezembro de 2013 , 
no setor de turismo formal esta foi de $\mathrm{R} \$ 1.511,00$, sendo que somente algumas ocupações nas atividades de alojamento, agências de viagens e transporte aéreo tiveram remuneração equivalente à média nacional $(\mathrm{R}$ $\$ 1.938,00$ ), observando que se trata de atividades com índices de formalidade maior (sobretudo transporte aéreo) e que a região sudeste elevou a média geral (Ipea, 2015, pp. 09-19 passim). No nordeste, região marcada pelo turismo de sol e mar, o pagamento médio registrado nas ACTs foi de $\mathrm{R} \$ 1.082,00$, frente a $\mathrm{R} \$ 1.706,00$ no sudeste.

Sendo a informalidade uma prática patente em turismo, principalmente quando se considera empreendedores menores em realidades dinamizadas por um mercado concorrencial (atendendo a empresas maiores, monopólios ou oligopólios), é possível que os pagamentos sejam ainda mais baixos ou, se alguns não o são, ficam comprometidas as garantias, tais como o seguro desemprego, contribuição previdenciária, Fundo de Garantia por Tempo de Serviço (FGTS), férias remuneradas, décimo terceiro. Por isso, Antunes (2013, p. 17) alerta que "se a informalidade não é sinônimo direto de condição de precariedade, sua vigência expressa, com grande frequência e intensidade, formas de trabalho desprovidas de direitos, as quais, portanto, apresentam similitude com a precarização".

Se os dados estatísticos apresentados podem indicar processos relacionados ao valor-capital, procuramos levantar casos concretos no sentido de verificar quais as condições efetivas de algumas ocupações em turismo, com destaque para o setor de alojamentos (hotéis, resorts, pousadas). Considerando que se trata do segmento com o segundo maior número de ocupações (atrás somente da categoria alimentação), deve-se considerar que tais estruturas têm participação significativa na economia daquelas realidades com dinâmicas movimentadas preponderantemente pelo turismo.

Nesse sentido, evidenciamos e detalhamos o cotidiano laborativo de um sujeito ao qual denominamos "cortês trabalhador terceirizado", contemplando as atividades de entretenimento que desenvolve em um resort que conjuga lazer e cursos técnicos no interior de São Paulo. Ele aponta o que é comumente praticado em unidades produtivas de hospitalidade assim categorizadas, chamando a atenção para o fato de que as terceirizaçóes de serviços ou daqueles sujeitos que ficam responsáveis pelos momentos lúdicos obedecem às entradas e saídas dos hóspedes, a sazonalidade e/ou aos períodos em que são promovidos eventos, questões essas que ajudam a caracterizar como incertas muitas das ocupações relacionadas ao turismo. Quadros enxutos e, portanto, estabelecidos aquém da medida do que é possível de ser normalmente realizado pelos grupos em questão materializam a intensidade e a extensão do trabalho: geralmente as chamadas "equipes de recreação" são contratadas de forma avulsa, ou seja, são pagas por hora ou por dia e, por isso, quanto mais o trabalho se estende, maior é a remuneração.

Tal mecanismo adotado, tanto no país "topten" (Trigo, 2012) quanto no Brasil, faz com que os expedientes citados (intensificação e extensão) sejam forçados pelo próprio trabalhador, seja para se auferir ganhos um pouco mais expressivos, seja para assinalar um possível diferencial de atuação, fato esse que pode aumentar as chances para trabalhos futuros. Importa evidenciar que o alargamento do tempo não se refere somente às horas diárias, as quais são de no mínimo 12 e podem chegar a 18 nas datas firmadas para as "brincadeiras noturnas" ou encenações de palco, mas contempla a quantidade de dias corridos estabelecidos pelo próprio prestador de serviços recreacionais dentro de um determinado período de atividade estipulado, uma vez que não é possível saber se haverá trabalho na semana seguinte, feriado ou época de férias. Garante-se o que é possível hoje diante das incertezas do amanhã.

A função requer paciência e cuidado no revezamento diário para o atendimento às diferentes faixas etárias: os monitores encarregados pelo desenvolvimento de atividades infantis devem receber as crianças, acompanhá-las aos banheiros, ajudar na troca de roupas, levá-las aos locais de alimentação e permanecerem atentos para que não deixem os espaços de recreação. Em relação aos adultos, as atividades nas piscinas e demais áreas de lazer demandam ainda mais atenção, uma vez que não são raros os casos de assédio sexual, os quais vão desde apalpadas até convites formais para "passeios". Dentre os conhecimentos exigidos para a ocupação, estão incluídos aqueles relativos a atrações circenses, encenação teatral, modalidades esportivas e 
organização de jogos e atividades em salão para os dias de chuva, sendo que a proficiência em outras línguas é também usual. Se o expediente pode variar de 12 a 18 horas, os momentos de parada fazem parte de alternâncias entre os colegas, mas geralmente são previstas duas por dia: cerca de trinta minutos para o almoço e o mesmo tempo para o jantar. Quando as "brincadeiras noturnas" entram no cardápio de entretenimentos em datas específicas, reserva-se um período de mais trinta minutos para o banho antes das atividades, uma vez que elas podem se estender até às duas horas da manhã. De qualquer maneira, tendo ou não o trabalho noturno, o material utilizado no dia deve ser organizado pelos próprios recreadores, de forma que tudo esteja pronto para as atividades do dia seguinte.

O acompanhamento dos hóspedes nos horários de almoço e jantar é uma prática que varia de empresa para empresa. No caso da experiência a respeito do trabalho no hotel de lazer no interior paulista, isso é realizado por um esquema de revezamento entre os monitores-recreacionistas, sendo que aqueles excluídos dessa incumbência devem se dirigir ao refeitório do complexo, diferenciado por sua simplicidade diante da estrutura luxuosa. Mas, se essa prática é usual em algumas unidades produtivas de serviços, em outras se exige o desmembramento entre trabalhadores e hóspedes nos poucos momentos livres dos primeiros, o que inclui os espaços frequentados pelos dois grupos, sendo alguns terminantemente proibidos de serem utilizados pelos empregados chamados de "colaboradores". Além disso, em empresas que separam os locais de refeição, nosso cortês trabalhador terceirizado relatou que há casos em que a comida servida aos funcionários é diferente daquela oferecida aos clientes, uma vez que se aproveita com os primeiros as sobras do "menu" do dia anterior. É digno de nota que os alojamentos ou instalações edificadas (e não raras vezes precárias) com a finalidade de permanência de empregados fixos e terceirizados é também uma estratégia empresarial, afinal, as horas não combinadas podem ser utilizadas à serviço dos empregadores como uma "gentileza" dos contratados.

Deve ser evidenciado que o "cortês trabalhador-terceirizado" personifica tipos de ocupaçóes comuns nas ACTs, sendo que o laboratório para o mais-valor que inclui expedientes empresariais para o acirramento da concorrência entre funcionários, a moradia no emprego e o tempo de trabalho para além dos contratos (formais) ou do combinado (na informalidade), envolve unidades produtivas de serviços de porte igual à citada, mas, também, as menores, podendo gerar reestruturações produtivas e repercussões socioespaciais significativas, principalmente naquelas destinações marcadas pelas vantagens de localização apontadas por Chesnais (1996).

A Ilha do Mel, no Paraná, pode ser apontada como exemplo. Sendo um referencial turístico do sul do Brasil, é atualmente uma área de proteção integral delimitada por duas unidades de conservação: uma Reserva Ecológica que abrange 95\% do seu território com restrições de utilização e visitação; e um Parque Estadual que contempla os outros $5 \%$, onde é possível a visita e permanência regulada. É nesse espaço que estão localizados os núcleos de Brasília e Encantadas, os quais servem como portas de entrada e onde estão situadas as principais atividades características do turismo (bares e lanchonetes, restaurantes, pequenas lojas de souvenirs, ambulantes, hotéis e pousadas). Empreendimentos turísticos de iniciativa de residentes, principalmente nos segmentos de alojamento (pequenas pousadas e campings) e alimentação que nada mais são do que residências adaptadas (atualmente em menor número) avizinham-se a pousadas de pequenos proprietários e a hotéis (também chamados de pousadas ou resorts) que, devido às estruturas maiores, exigem mais trabalhadores em épocas de alta temporada. Desde que foram instituídas as unidades de conservação, parte dos habitantes nativos que viviam principalmente da pesca artesanal e lá permaneceram acabaram buscando meios complementares de ganhos, sendo o turismo a principal alternativa. Com aproximadamente 1100 habitantes e somente 98 pescadores restantes em 2010 (IBGE, 2010), desse total 65\% exerciam alguma ocupação relacionada ao turismo, contudo, isso não representou um complemento significativo e a remuneração média mensal permaneceu próxima daqueles que continuaram a exercer apenas a atividade pesqueira-artesanal.

Segundo Fuzetti e Corrêa (2009, p. 621), os sujeitos que viviam somente da pesca declararam um ganho mensal de $\mathrm{R} \$ 425,00$ em 2009, enquanto aqueles que tinham uma atuação complementar direta no turismo, 
o montante não ultrapassava $\mathrm{R} \$ 585,00$, atrelado, para muitos deles, às épocas de alta temporada. Os pesquisadores identificaram, também, que se a pesca antes do advento das visitações e permanência em larga escala (após a década de 1990) era uma atividade coletiva, agora ela é realizada de forma mais individualizada. Compreendemos que a cooperação foi quebrada não pelo surgimento do turismo como prática social, mas como força produtiva que modificou progressivamente a hierarquização do trabalho, a qual foi reconfigurada e adquiriu outro sentido para atender não mais ao coletivo, mas a propriedade em sua forma privada como meio para a geração de valor-capital em sua ânsia natural expansionista.

É o que se percebe com as unidades de hospedagem A, B, C e D: seus proprietários não residem na ilha e possuem outros negócios ou profissões, sendo que essas contam com gerentes que moram no próprio estabelecimento. São sujeitos que administram os empreendimentos em períodos de baixa e alta estação, em ocupações particularizadas pela polivalência, uma vez que a gestão inclui serviços de limpeza, recepção, reservas, compras, pequenos reparos (ou a contratação de pessoal para esse fim) e atendimento aos hóspedes. Mas, se os empregados-moradores são poucos durante quase todo o calendário, de dezembro até o período de carnaval esses devem buscar os trabalhadores sazonais. A empresa A, que é categorizada como resort, por contar com mais unidades habitacionais mantêm aproximadamente dez empregados denominados "colaboradores" na baixa temporada, chegando a contratar temporariamente mais de 40 na alta estação. Tais empregados ficam em alojamentos do próprio empreendimento e, também, em casas ou pequenas pousadas locadas para esse fim. A unidade B estendeu horizontal e verticalmente o negócio: adquiriu outra pousada e abriu um restaurante em local separado para atender, além dos hóspedes, o público em geral. Além disso, construiu um alojamento próprio para os empregados que vem para a alta estação. Tanto o proprietário da empresa $\mathrm{C}$ como o da $\mathrm{D}$, contam também com restaurantes como negócios associados e complementares, sendo que os gerentes multifunções de todas elas administram também esses estabelecimentos. Observouse que a estratégia de manter os empregados morando nos estabelecimentos é corrente, além de uma alta rotatividade nas ocupações, reclamação essa levantada pelos gerentes-moradores ao afirmarem que parte dos funcionários-sazonais (muitos informais) não corresponde a contento às exigências laborais.

$\mathrm{Na}$ dinâmica atribuída à Ilha do Mel pelo turismo tem papel relevante as unidades de conservação que o fomentam de forma direta ou indireta: seus corredores limitados à circulação a pé ou de bicicleta e o número máximo de visitantes/dia passam a impressão de um espaço resguardado, de forma que os reflexos socioespaciais da valorização do valor ficam até certo ponto camuflados pela legislação ambiental e pela ideologia que propagandeia a ideia do "desenvolvimento sustentável", como se suas prescrições tivessem condições de aplicabilidade prática em um tempo histórico regulado pelo "sociometabolismo do capital" (Mészáros, 2006). Os pequenos estabelecimentos; as normas concernentes às edificações; as restrições que impedem o surgimento de aglomerados habitacionais marginais condizentes com os baixos salários ou pagamentos advindos do turismo; a prática das unidades produtivas maiores em servirem como locais de reprodução dos proletários-sazonais do turismo; e a proximidade de Paranaguá e Pontal do Sul como cidades que fornecem mão de obra na alta estação, colaboram com a falsa noção de "turismo com bases localizadas".

Apesar de haver restrições impostas pelo Estado em relação ao uso do solo e proibição de venda dos terrenos aos que não são nativos da Ilha do Mel, o termo de posse é negociado e os negócios associados à turistificação acarretaram a valorização da terra e dos imóveis, sendo que aqueles trabalhadores que venderam suas posses, deixaram a ilha e resolveram voltar em algum momento, somente puderam retornar como mão de obra barata e sem chances de readquiri-las. Tais moradores tradicionais, uma vez absorvidos total ou parcialmente em serviços gerais, carregamento de malas, reparos, manutenção de estabelecimentos comerciais, são postos para gerar valor a mais em especial entre o natal e o carnaval. A possibilidade de produzir algo por meios próprios é restrita pelas normas das unidades de conservação, mas, essencialmente, pela relação de assalariamento a qual foram submetidos com o advento do turismo, a qual inibiu, interditou ou associou outras formas de produção e sustento coletivas diante do alicerçamento de relações pautadas pela separação entre meios produtivos 
(principalmente a terra) e produtores diretos. Não é preciso dizer que tal convívio determina tanto o trabalho em excesso, próprio à dinâmica do capital, como a falta dele.

\section{CONSIDERAÇões FINAIS}

Mesmo que no turismo o empregado esteja muito mais próximo do consumidor do que o operário da indústria, a orientação para que estampe um sorriso e o referencial lúdico/diferente do espaço (de consumo) somam-se à mente reificada, fato que ajuda a obstruir as relações laborativas como relações históricas e seu primordial propósito, qual seja: o bem receber não para os sujeitos, mas como veículo essencial para a troca. Assim, em muitas localizações e unidades produtivas de serviços, o trabalho projeta-se de forma invertida, sendo, não raras vezes, adjetivado como "gostoso", "agradável", "aprazível", "interativo". Com o intuito de contribuir com a reinversão dessas ideias ou, ao menos, desmitificá-las, apontamos exemplos concretos da materialidade socioespacial dinamizada em seus fundamentos pelo capital nos serviços ligados à hospitalidade.

Os poucos casos apontados refletem configurações gerais das ocupações no Brasil, mas não diferem, em termos gerais, daquelas situadas nessas atividades em países detentores de um "turismo respeitado" (Trigo, 2012), como a França, o que inclui: a posição fragilizada de trabalhadores diante do caráter informal de parte significativa das contratações; a mescla do tempo de trabalho com o suposto tempo liberado via práticas da moradia no emprego e/ou acirramento da competitividade entre trabalhadores; a sazonalidade dos postos de trabalho própria à realidade de diversas cidades e localidades turísticas, fato que impõe intensidade e extensão associada à insegurança quanto a recondução ao trabalho em outras temporadas e o sustento em períodos de baixa demanda; a debilidade organizativa dos trabalhadores fomentada pelo discurso do empreendedorismo individual independente da materialidade social financiado por empresas, universidades, Estado e meios de comunicação representativos das classes economicamente dominantes; além de salários substancialmente mais baixos que a média nacional, mesmo tratando-se de trabalhos que exigem permanência em períodos de férias, finais de semana, feriados e disponibilidade total para atendimentos de urgência.

Essas práticas de trabalho tendem a se instalar de forma dominante com a absorção das vantagens de localização em termos produtivos por e para o capital. A essa fluidez quase são inexistentes as barreiras, mas, quando elas aparecem (tal como o Forum Social des Saisonniers), não são poucas as articulações que se valem das formas aparentes do espaço e das "boas práticas de gestão" para nutrir os laboratórios do trabalho produtivo, promovendo a separação entre educação/preparação e economia política. Se, conforme aponta Marx (2008, v. I, p. 271), o capital é um "vampiro" e os trabalhadores em turismo (e sua maioria mulheres e jovens desorganizados politicamente, indivíduos na informalidade, imigrantes, além de crianças) estão desenraizados de sua classe social e centrados em suas especificidades técnicas (como quer a ideologia científica neopositivista), quanto mais suas atividades são abarcadas como meios concretizantes de valores para a troca, mais as relações centradas nos processos expansionistas do capital irão permear as realidades socioespaciais, sendo tais sujeitos entendidos como corpo social com sangue farto. E a contradição a ser ressaltada é esta: o tempo livre de alguns se transforma em tempo de consumo de uma espécie de lazer e entretenimento calcados em ordenações laborativas impetuosas em espaços com ares de harmonia, descontração e festividade.

\section{REFERÊNCIAS}

Antunes, R. L. C. (2009). Os sentidos do trabalho: ensaio sobre a afirmação e a negação do trabalho (2a. ed.). São Paulo: Boitempo (Mundo do Trabalho).

Antunes, R. L. C. (2013). A nova morfologia do trabalho e suas principais tendências: informalidade, infoproletariado, (i)materialidade e valor. In Antunes, R. L. C. (Org.). Riqueza e miséria do trabalho no Brasil II. São Paulo: Boitempo (Mundo do Trabalho). 
Berodias, S. (2012, novembro). Les saisonniers et le role de l'Etat dans le tourisme. Entrevistada por Rodrigo Meira Martoni.

Braverman, H. (1980). Trabalho e capital monopolista: a degradação do trabalho no século XX. (N. Caixeiro, Trad.). (2a.ed.). Rio de Janeiro: Zahar.

Brasil/Ministério do Turismo. (2014). Mais de 6,4 milhões de turistas estrangeiros visitaram o Brasil em 2014. Recuperado de: http://www.turismo.gov.br/ultimas-noticias/5227-mais-de-6,4-milh\%C3\%B5es-de-turistasestrangeiros-visitaram-o-brasil-em-2014.html.

Brasil/Ministério do Turismo. (2014). Turismo movimenta $\mathrm{R} \$ 492$ bilhões no Brasil. Recuperado de: http://www.t urismo.gov.br/ultimas-noticias/957-turismo-movimenta-r-492-bilhoes-no-brasil.html.

Christin, R., Bourdeau, P. (2011). Réveillons le touriste qui sommeille en nous! In Christin, R., Bourdeau, P. (Orgs.). Le tourisme: émancipation ou contrôle social? (pp. 07-10). Bellecombe-en-Bauges, FR: Éditions du Croquant.

Christin, R. (2011). Le tourisme enfermé. In Christin, R., Bourdeau, P. (Orgs.) Le tourisme: émancipation ou contrôle social? (pp. 11-45) Bellecombe-en-Bauges, FR: Éditions du Croquant.

Chesnais, F. (1996). A mundialização do capital. (S. Finzi Foá, Trad.). São Paulo: Xamã.

Dethyre, R. (2007). Avec les saissoniers: une experience de transformation du travail dans le tourisme social. Paris: La Dispute.

Fuzetti, L., Corrêa, M. F. M. (2009). Perfil e renda dos pescadores artesanais e das vilas da Ilha do Mel, Paraná, Brasil. B. Inst. Pesca, 609-621. Recuperado de: ftp://ftp.sp.gov.br/ftppesca/35_4_609-621.pdf.

Instituto Brasileiro de Geografia e Estatística - IBGE (2010). Censo 2010. Recuperado de: http://censo2010.ibge.g ov.br/

Institut National de la Statistique et des Études Économiques de la France - Insee (2012). Emplois salariés dans le tourisme : um poids localement important (França) Recuperado de: http://www.insee.fr/fr/themes/document .asp?reg_id=7\&ref_id=19247\&page=six_pages $/ 6$ p_n145/6pages_n145page2.htm

Instituto de Pesquisa Econômica Aplicada - Ipea. (2013). Quarto relatório anual com estimativas definitivas da ocupação formal e informal, a partir dos últimos dados divulgados da RAIS e da PNAD, para o Brasil, região Centro-Oeste e Distrito Federal. Brasília: Ipea. Recuperado de: http://www.ipea.gov.br/portal

Instituto de Pesquisa Econômica Aplicada - Ipea / Ministério do Turismo. (2015). Relatório com as estimativas da caracterização da ocupação formal e informal do turismo, com base nos dados da RAIS e da PNAD 2013, para o Brasil e regiões. Brasília: Ipea. Recuperado de: http://www.ipea.gov.br/portal/images/stories/ PDFs/150317_estimativas_ocupacao-2015.pdf

Kosik, K. (1976). A dialética do concreto. (C. Neves e A. Toríbio, Trad.). 2.ed. Rio de Janeiro: Paz e Terra.

Lefebvre, H. (2008). Espaço epolítica. (M. M. de Andrade e S. Martins, Trad.). Belo Horizonte: Ed UFMG.

Marx, K. (2008). O Capital: crítica da economia política. (Livro I, volume I). (R. Sant'Anna, Trad.) (26a.ed.). Rio de Janeiro: Civilização Brasileira.

Marx, K. (2001). O Capital: crítica da economia política. (Livro I, volume II). (R. Sant'Anna, Trad.). (17a. ed.). Rio de Janeiro: Civilização Brasileira.

Marx, K. (2008). O Capital: crítica da economia política. (Livro III, volume IV). (R. Sant'Anna, Trad.). Rio de Janeiro: Civilização Brasileira.

Mészáros, I. (2006). Para além do capital. (P. C. Castanheira e S. Lessa, Trad.) São Paulo: Boitempo.

Ouriques, H. R. (2005). A produção do turismo: fetichismo e dependência. Campinas: Alínea.

Blog Trigo, L. G. G. (2014). Você vive em um país perfeito para viajar [Blog]. Recuperado de: http://luiztrigo.blogsp ot.com.br/2014/01/voce-vive-em-um-pais-perfeito-para.html.

Blog Trigo, L. G. G. (2012). "Regulamentação" do turismólogo: enganos e engodos [Blog]. Recuperado de: http://luiz trigo.blogspot.com.br/2012/01/regulamentacao-do-turismologo-enganos-e.html. 


\section{Notas}

1 “[... capturando o desejo turístico para fixá-lo em certas práticas, em certos lugares, à certas condições”. Tradução nossa, assim como as seguintes.

2 "O turismo se vale [...] da realidade a fim de lhe dar uma aparência adequada, conforme os critérios partilhados e julgados aceitáveis em termos estéticos, de segurança, econômicos e ambientais [...]”.

3 Para fins de delimitação, caracterização e estatística, o Instituto de Pesquisa Econômica Aplicada (Ipea) considera quase todas as Atividades Características do Turismo (ACTs) do conjunto instituído pela Organização Mundial do Turismo (OMT). As ACTs estão atualmente divididas em oito grupos: agências de viagem; alojamento; alimentação; cultura e lazer (atividades de entretenimento, recreação, espetáculos e similares); transporte terrestre; transporte aéreo; transporte aquaviário; e aluguel de transportes (Ipea, 2013, p. 07).

4 TRIGO, L.G.G. "Você vive em um país perfeito para viajar". 02 jan. 2014. Blog de Luiz Trigo. Disponível em: http:// luiztrigo.blogspot.com.br/2014/01/voce-vive-em-um-pais-perfeito-para.html. Acesso em: 14 jan. 2018.

5 TRIGO, L. G. G. “'Regulamentação’ do turismólogo: enganos e engodos”. 19 jan. 2012. Blog de Luiz Trigo. Disponível em: http://luiztrigo.blogspot.com.br/2012/01/regulamentacao-do-turismologo-enganos-e.html. Acesso em: 14 jan. 2018.

6 Em "Os sentidos do trabalho", Antunes detalha que esta classe contempla os assalariados, os trabalhadores da economia informal, os contratados por meio período, os terceirizados, os trabalhadores precarizados dos setores primário, secundário e terciário e, também, os desempregados. Desses, estão excluídos os proprietários e gestores do capital, bem como aqueles que, "de posse de um capital acumulado, vivem da especulação e dos juros" (Antunes, 2009, p. 103).

7 "tipos de espaços"

8 "O recenseamento da população é uma fonte que permite avaliar o emprego não assalariado [informais] exclusivamente para as atividades consideradas como $100 \%$ turísticas".

9 "Os empregos no turismo, quer sejam sazonais ou não, são menos qualificados, mais frequentemente em tempo parcial e com menor frequência regidos por contratos de trabalho em tempo indeterminado $[\mathrm{CDI}]$ do que a média”. Disponível em: http://www.insee.fr/fr/themes/document.asp? reg_id=7\&ref_id=19247\&page=six_pages/6p_n145/6pages_n145page2.htm. Acesso em: 14 fev. 18 .

10 "Dentre os dois milhões de empregos conhecidos e reconhecidos no setor de turismo, muitos são de caráter sazonal - ao menos $25 \%$ - com tendência a aumentar".

11 "Contrato com Duração Determinada"

12 "O contrato sazonal no turismo serve como um laboratório para a precarização do trabalho, pois o gestor ao se confrontar com as formas de contratação dirá: nós inserimos novamente a lâmina onde pensamos encontrar menos resistência".

13 “[...] particularmente em razão do trabalho informal em hotéis, cafés e restaurantes [...]"

14 Confederação Central do Trabalho. Trata-se da central sindical francesa.

15 "Juventude Operária Cristã".

16 “A temporada é curta para o turismo de verão, o que leva os empregadores a tentar realizar o maior volume de negócios durante esse período. As organizações sindicais denunciam, por exemplo, o fato de os 'estabelecimentos' litorâneos empregarem jovens mal remunerados executando mais de cem horas de trabalho por semana".

17 Disponível em: http://www.entreprises.gouv.fr/files/files/directions_services/etudes-et-statistiques/stats-tourisme/ chiffres-cles/2015-Chiffres-cles-tourisme-FR.pdf. Acesso em: 14 fev. 2018.

18 Dados retirados do observatório informativo do "Turismo na França (Veille Info). Tourisme en France - 2013-2014: poids et impacts économiques. Disponível em: http://www.veilleinfotourisme.fr/tourisme-en-france-en-2014-poidset-impacts-economiques--92345.kjsp. Acesso em: 12 dez. 2017.

19 Emplois salariés dans le tourisme: un poids localement important. Disponível em: http://www.insee.fr/fr/ themes/document.asp?reg_id=7\&ref_id=19247\&page=six_pages/6p_n145/6pages_n145page2.htm. Acesso em: 13 dez. 2017.

20 BERODIAS, S. Les saisonniers et le rôle de l'Etat dans le tourisme. Paris. 09 dez. 2012. Entrevista concedida ao autor.

21 Empresa estatal de produção e fornecimento de energia da França.

22 Smic (salaire minimum interprofessionnel de croissance) en France. Disponível em: http://www.les-horaires.fr/ pratique/smic-horaire.php. Acesso em: 14 dez. 2017.

23 "O Estado contribui com a precariedade do emprego, pois ele pouco leva em conta a realidade do trabalho sazonal".

24 "O relatório Gaymard sobre a polivalência".

25 "O relatório Anicet Le Pors sobre os empregos sazonais"

26 "O relatório Simon sobre alojamento"

27 "O relatório Vansonn acerca dos empregos em montanhas 
28 "passados mais de 25 anos, concretamente, nada realmente surgiu para melhorar a vida e as condições de trabalho dos empregados sazonais, então em 25 anos o número dessas ocupações aumentou".

29 Disponível em: http://www.turismo.gov.br/ultimas-noticias/5227-mais-de-6,4-milh\%C3\%B5es-de-turistasestrangeiros-visitaram-o-brasil-em-2014.html: Acesso em: 14 dez. 2017. Trabalhamos com dados de 2014, pois trata-se de um período com empregabilidade ainda em alta e movimentação econômica impulsionada pela Copa do Mundo.

30 http://www.turismo.gov.br/ultimas-noticias/957-turismo-movimenta-r-492-bilhoes-no-brasil.html. Acesso em: 16 dez. 2017. 